\title{
SLEEP DISORDERS AND STARTING TIME TO SCHOOL IMPAIR BALANCE IN 5-YEAR-OLD CHILDREN
}

\author{
Cristiane Aparecida Moran", Luciane B.C. Carvalho², Lucila B.F. Prado³, Gilmar F. Prado ${ }^{4}$
}

\begin{abstract}
Objective: To verify if sleep disorders and differents starting time to school have impaired motor skills in 5-year-old children. Method: Cross-sectional design consisting of 132 children with sleep disorders and 136 normal controls of the public school in the city of São Paulo. The group with sleep disorders was identified based on a questionnaire, and motor tests for global motor coordination, fine motor coordination, perceptual-motor coordination, and static and dynamic balance were applied in all children. Results: In the static balance test, more specifically in the sharpened Romberg (Tandem) test, $34 \%$ of boys from the study group, who studied in the morning, failed the test $(p<0.05)$. In the single leg stance test, $62 \%$ of boys from the study group who studied in the morning failed $(p<0.05)$. Conclusion: This study suggests that sleep disorders may interact with the school period and alter motor performance, especially in boys studying in the morning.
\end{abstract}

KEY WORDS: sleep disorders, preschool children, motor performance, balance, cronobiology.

\begin{abstract}
Distúrbios do sono, período escolar e equilíbrio em crianças com $\mathbf{5}$ anos de idade
RESUMO - Objetivo: Verificar se distúrbios do sono e diferentes períodos escolares comprometem as habilidades motoras de crianças de 5 anos. Método: Realizou-se estudo transversal com 132 crianças com distúrbio do sono e 136 controles normais de escolas públicas da cidade de São Paulo. Foram utilizados questionários para distúrbios do sono e testes para coordenação motora global, motora fina, percepto-motora, equilíbrio estático e dinâmico. Resultados: No teste de equilíbrio estático, mais especificamente na p rova pé ante pé, $34 \%$ dos meninos do grupo estudo, que estudavam no período da manhã, falharam no teste $(p<0,05)$. Na prova de apoio monopodal, $62 \%$ dos meninos do grupo estudo, que estudavam no período da manhã, falharam no teste $(p<0,05)$. Conclusão: Este estudo sugere que os distúrbios do sono podem interagir com o período escolar e alterar a performance motora, principalmente de meninos que estudam no período da manhã.
\end{abstract}

PALAVRAS-CHAVE: distúrbios do sono, crianças pré-escolares, performance motora, equilíbrio, cronobiologia.

The prevalence of sleep disorders in preschool children ranges from 25 to $37 \%$, but only few studies have associated sleep disorders with cognitive performance in this population and only some reports in the international literature alert to the possible impairment of motor skills resulting from sleep disorders in this age group ${ }^{1-13}$. Recent studies have suggested that sleep might particularly be important for the consolidation of proceduralbased skill learning ${ }^{14}$. Furth e rm ore, variables such as circadian rhythm may increase the effects of sleep disorders in terms of both cognitive and motor functions ${ }^{15}$.

Motor development can be accompanied by sleep problems $s^{8,15-17}$. Training of motor skills followed by a night of sleep results in a $20 \%$ increase in motor performance speed without loss of accuracy, a fact not observed when the subjects remain awake after training, suggesting that sleep is critical for the consolidation of certain memory types and basic neurophysiological processing required for skill learn in ${ }^{14}$. Selective sleep deprivation can impair the acquisition of a motor activity, and stage 2 non-REM sleep, in addition to REM sleep and slow-wave sleep, might be involved in overnight gain of motor skills ${ }^{14,16}$. Investigations on motor deficits in different age groups and their eventual association with sleep disturbances are neces-

Federal University of Sao Paulo (UNIFESP), Sao Paulo SP, Brazil: ${ }^{1}$ Physiotherapist, postgraduate student, Department of Intern al Medicine; ${ }^{2}$ Psychologist, PhD, Department of Neurology; ${ }^{3}$ Pediatrician, MD, PhD, Department of Neurology; ${ }^{4} \mathrm{~N}$ e u rologist, MD, PhD, Departments of Internal Medicine and Neurology.

Received 19 November 2004, received in final form 24 February 2005. Accepted 11 April 2005.

Dr. Gilmar Fernandes do Prado - Rua Claudio Rossi 404 - 01547-000 SP - Brasil. E-mail: gilmar.dmed@epm.br 
sary because of the potential benefits for this population, since the identification of changes in neuromotor development permits adequate guidance for the child within the skills expected for his/her age.

The objective of the present study was to 1) determine whether children with sleep disorders show impaired motor skills resulting from sleep disturbances and 2) the influence of the association between sleep disorders and starting time to school on motor skills.

\section{METHOD}

Subjects and study place - We called for a lecture on sleep disorders 1382 children's parents of 5 elementary public schools from Ermelino Matarazzo and São Miguel Paulista periferic region of São Paulo, SP, Brazil. A total of 15 meetings were realized and 780 parents $(56 \%)$ attended to them. At that time 780 questionnaires were distribuited. Five hundred and thirty five re $t u$ rned and we excluded 161 for incorrect filling in or who presented one or more of the following deficits: pre-existing visual, osteomuscular and/or neurological deficits, chil$\mathrm{d}$ ren who did not fit the age, and children who refused to participate or did not appear on the day of application of the test.

Finally a total of 374 preschool children aged 5 years enrolled in schools belonging to the east zone of the city of São Paulo, Brazil, were studied to determine possible changes in motor skills associated to sleep disorders. Of the 374 children, 132 (35\%) had sleep disorders, and all were included in the study. Among the 242 possible children without sleep disorders, 136 were randomily selected to comprise the control group. The number of children selected for the control group depended on the number of children with sleep disorders in each school period, i.e., morning, intermediate and afternoon, and we did the selection according to standard sampling procedures (standard error formula) what allowed a number of 288 subjects. We achieved a total of 268 children for the study and control groups much close from the calculated number. Children in the morning period studied from 7:00 to 11:00 h, those in the in te rmediate period from 11:00 to 15:00 $\mathrm{h}$, and those in the afternoon period from 15:00 to 19:00 h. All children were evaluated in the school during school period.

Diagnosis of sleep disorders - Sleep disorders were diagnosed using The Sleep Disturbance Scale for Children (SDSC) adapted for Brazilian Portuguese ${ }^{18}$, what includes: parasomnias disorder of initiating and maintaining sleep, excessive daytime sleep, sleep hyperhidrosis and sleep $b$ reathing disorders. For the porpuse of this study we analyzed the sleep disorders group as a whole, because our primary interest were to compare any kind of sleep dis o rders to a control group. The questionnaires were filled out during the meeting by parents or relatives guided by the researcher.

The Research Ethics Committee of the Federal University of São Paulo approved the study, and the parents or responsible persons signed an informed consent form.

Motor skill assessment - To detect changes in motor skills (static balance, dynamic balance, global motor c o o rdination, perceptual-motor coordination, and fine motor coordination) we used 10 instruments (toys). Because sleep disturbance were rarely, if once, taking in account in previous motor performance test and because the number of tests for five years old children were generally reduced. The study design was done in a comparative fashion, we decided to select 10 instruments (toys) more likely to assess motor disturbance in this age. Failure was considered to have occurred in a test when 1) the child did not perform the test. The child avaliated what was proposed and after a varied amount of hesitation decide not to perform the test fearing not to accomplish the required task, disclosing his/her potencial disability according to the global impression of the examiner (blind to the groups), 2) the child tried and failed. Analysis of the child's perf o rmance in all 10 tests permitted to determine whether or not the child had impaired motor skills.

The same examiner (C.A.M.) conducted all tests and was unaware of whether the child belonged to the study or control group.

Static balance. This parameter was evaluated using two tests: a) the single leg stance (10 s) and b) sharpened Romberg (Tandem) (10 s). In the single leg stance test, the child remained standing with plantar support on one foot only (chosen by the child itself), with the other leg flexed at a right angle and the eyes open. The child failed the test when the foot touched the floor. In the sharpened Romberg (Tandem) test, the child remained standing with plantar support of one foot, with the tip of one foot close to the heel of the other and the eyes open. The child failed the test when moving the foot of initial support.

Dynamic balance. These parameters were assessed using two tests: a) foot by foot gait and b) jumping with the two feet together. In the foot-by-foot gait test, the child walked forward on a 2-m straight line, placing the heel of one foot close to the tip of the other. The child failed the test when his/her feet left the line during the course. In the jumping test, the child moved forward for a distance of $5 \mathrm{~m}$ jumping with the two feet together. The child failed the test when he/she was unable to jump forward, or was only able to perform the test with the feet apart.

Global motor coordination. This parameter was evaluated using two tests: a) playing hopscotch and b) skip- 
ping rope. In the hopscotch game, due to the age of the children studied perf o rmance was only evaluated during the first phase of the game, which consisted of altemately leaping in double (bipedal support) and single boxes (monopodal support using the preferred lower limb). The boxes were square measuring $32 \mathrm{~cm}$ on each side and forming 10 contiguous and alternating squares. The child failed the test when he/she was unable to rhythmically and consecutively alternate one foot/two feet, as he/she leaped on one or two boxes. Skipping was perf o rmed with the help of the examiner who swung a $2.72-\mathrm{m}$ rope. The child was asked to skip the rope in a single attempt. The test failed when the child was unable to skip the rope.

Perceptual-motor coordination. This parameter was evaluated using two tests: a) key and b) pyramid tests. In the key test, the child was instructed to place a key in a lock simulating a conventional $7.5-\mathrm{cm}$ lock fixed to a rectangular wooden support whose sides measured 26.5 and $19 \mathrm{~cm}$. A Byzantine type key with a 7-cm axis, with the head measuring $2 \times 1.5 \mathrm{~cm}$ and the stem $1 \times 1$ $\mathrm{cm}$, was used. The child failed the test when he/she was unable to place the key in the lock. In the pyramid test, the child observed a quadrangular pyramid (base: 19 $\mathrm{cm}$, height: $2 \mathrm{~cm}$ ) consisting of 10 transversely sectioned consecutive pieces being mounted for about $5 \mathrm{~s}$. The pyramid was then dismantled in front of the child, and the child was asked to assemble it again. The child failed the test when the pyramid had fewer than 10 pieces or the contiguity of the transverse sections was incorrect.

Fine motor coordination. This parameter was assessed using two tests: a) tying a simple knot and b) buttoning a shirt. In the simple knot test, the child tied a simple knot in a pedagogic wooden shoe $(14 \times 7 \mathrm{~cm})$ fixed to a quadrangular wooden base $(19.5 \mathrm{~cm})$. The child failed the test when he/she only tangled the laces,

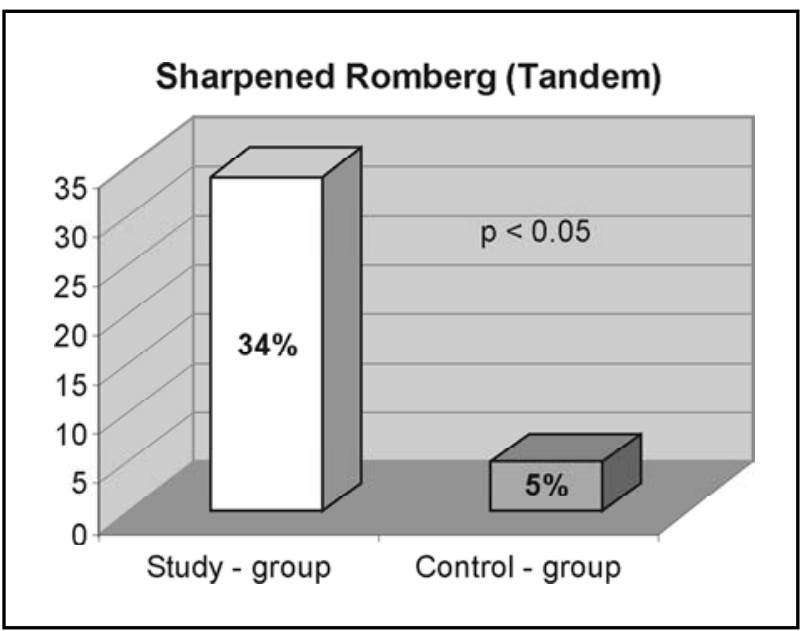

Fig 1. Static balance: performance in the sharpened Romberg (Tandem) test of boys with sleep disorders attending school in the morning. without crossing them and inverting their position. In the shirt-buttoning test, the child had to button two buttons of the shirt of a doll. The buttons measured 2 $\mathrm{cm}$ in diameter and were spaced $3 \mathrm{~cm}$ apart, measures appropriate for the execution of this task in this age group ${ }^{19}$. The child failed the test when he/she was unable to button the shirt.

Statistical analysis - The children were stratified into two groups (control and study group) and the results were analyzed statistically by the chi-square and Fisher tests. The variables enroled were: gender, starting time to school (morning, intermediate and afternoon). The test chi-square was used across groups (sleep disorders versus control, genders and starting time periods on each outcome measure, while Fisher's exact tests were used across group within each gender and time period on each dependent variable. We considered significant $p<0.05$.

\section{RESULTS}

Of the 268 children studied, 141 (53\%) were boys aged 5 years. The study group consisted of 132 children, $79(60 \%)$ of them boys, and the control group consisted of 136 children, 62 (45\%) of them boys. Boys and girls in the control group had the same motor performance test.

Motor performance did not differ significantly between 5-year-old children with and without sleep disorder in most of the 10 tests applied (Table $1 \mathrm{~A}$ and $1 \mathrm{~B})$.

The only difference between the study and control groups was observed in terms of static balance (both in the single leg stance and sharpened Romberg (Tandem) tests) for boys who studied in

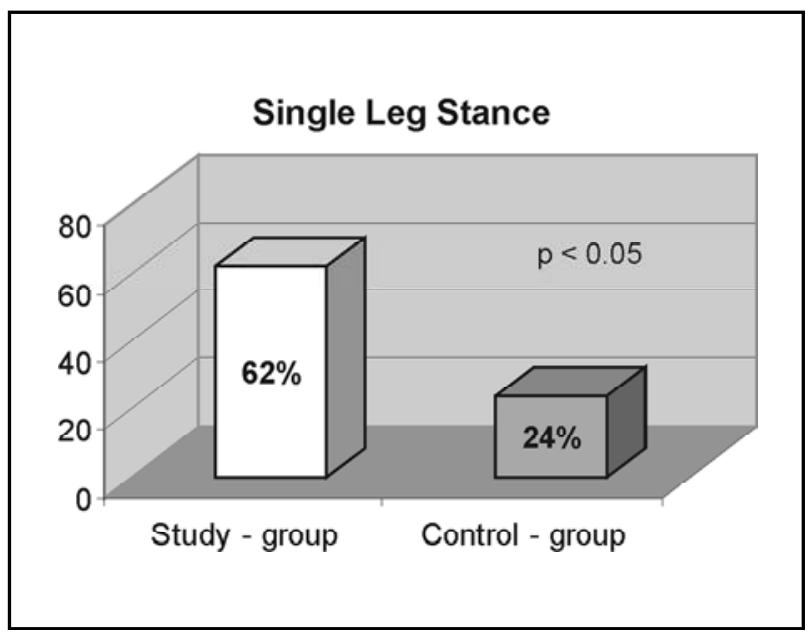

Fig 2. Static balance: performance in the monopodal stance test of boys with sleep disorders attending school in the morn ing. 
Table 1A. Absolute and relative values of alterations in the motor skill tests observed for boys and girls with sleep disorders attend ing different school periods.

\begin{tabular}{|c|c|c|c|c|c|c|c|c|c|c|c|c|c|c|c|}
\hline \multirow[t]{3}{*}{ Motor skill } & \multirow[t]{3}{*}{ Test } & \multicolumn{6}{|c|}{ Boys } & \multicolumn{6}{|c|}{ Girls } & \multicolumn{2}{|c|}{ Total } \\
\hline & & \multicolumn{2}{|c|}{ M } & \multicolumn{2}{|c|}{ I } & \multicolumn{2}{|c|}{ A } & \multicolumn{2}{|c|}{ M } & \multicolumn{2}{|c|}{1} & \multicolumn{2}{|c|}{$A$} & \multirow[b]{2}{*}{$\mathrm{N}$} & \multirow[b]{2}{*}{$\%$} \\
\hline & & $\mathrm{N}$ & $\%$ & $\mathrm{~N}$ & $\%$ & $\mathrm{~N}$ & $\%$ & $\mathrm{~N}$ & $\%$ & $\mathrm{~N}$ & $\%$ & $\mathrm{~N}$ & $\%$ & & \\
\hline \multirow[t]{2}{*}{ Static balance } & Single leg & 16 & $62 *$ & 11 & 48 & 17 & 59 & 11 & 55 & 9 & 50 & 12 & 71 & 76 & 57 \\
\hline & Tandem & 9 & $34 *$ & 4 & 17 & 2 & 7 & 2 & 10 & 1 & 5 & 3 & 18 & 21 & 16 \\
\hline \multirow[t]{2}{*}{ Dynamic balance } & Gait & 3 & 12 & 1 & 4 & 2 & 7 & 0 & 0 & 0 & 0 & 1 & 5 & 7 & 5 \\
\hline & Jumping & 3 & 8 & 0 & 0 & 2 & 7 & 0 & 0 & 2 & 11 & 1 & 5 & 7 & 5 \\
\hline Global motor & Hop-scotch & 14 & 54 & 8 & 35 & 14 & 48 & 8 & 40 & 6 & 33 & 6 & 35 & 56 & 42 \\
\hline coordination & Skipping rope & 16 & 62 & 16 & 70 & 20 & 69 & 11 & 55 & 13 & 72 & 14 & 82 & 90 & 68 \\
\hline \multirow[t]{2}{*}{ Perceptual-motor } & Key & 1 & 4 & 0 & 0 & 3 & 10 & 1 & 5 & 0 & 0 & 0 & 0 & 5 & 4 \\
\hline & Pyramid & 18 & 69 & 19 & 83 & 23 & 79 & 15 & 75 & 13 & 72 & 13 & 76 & 101 & 76 \\
\hline Fine motor & Buttoning & 4 & 15 & 1 & 4 & 4 & 14 & 0 & 0 & 0 & 0 & 0 & 0 & 9 & 7 \\
\hline coordination & Simple knot & 18 & 69 & 18 & 78 & 21 & 72 & 9 & 45 & 8 & 44 & 6 & 35 & 80 & 60 \\
\hline Total & & 101 & 22 & 78 & 17 & 108 & 24 & 57 & 13 & 52 & 12 & 56 & 13 & 452 & \\
\hline
\end{tabular}

$M$, morning period; I, intermediate period; $A$, afternoon period; * $p<0.05$.

Table 1B. Absolute and relative values of alterations in the motor skill tests observed for boys and girls of the control group attend ing different school periods.

\begin{tabular}{|c|c|c|c|c|c|c|c|c|c|c|c|c|c|c|c|}
\hline \multirow[t]{3}{*}{ Motor skill } & \multirow[t]{3}{*}{ Test } & \multicolumn{6}{|c|}{ Boys } & \multicolumn{6}{|c|}{ Girls } & \multicolumn{2}{|c|}{ Total } \\
\hline & & \multicolumn{2}{|c|}{$\mathrm{M}$} & \multicolumn{2}{|c|}{1} & \multicolumn{2}{|c|}{ A } & \multicolumn{2}{|c|}{$\mathrm{M}$} & \multicolumn{2}{|c|}{1} & \multicolumn{2}{|c|}{$A$} & \multirow[b]{2}{*}{$\mathrm{N}$} & \multirow[b]{2}{*}{$\%$} \\
\hline & & $\mathrm{N}$ & $\%$ & $\mathrm{~N}$ & $\%$ & $\mathrm{~N}$ & $\%$ & $\mathrm{~N}$ & $\%$ & $\mathrm{~N}$ & $\%$ & $\mathrm{~N}$ & $\%$ & & \\
\hline \multirow[t]{2}{*}{ Static balance } & Single leg & 5 & $24^{*}$ & 9 & 43 & 11 & 52 & 15 & 60 & 11 & 48 & 9 & 38 & 60 & 44 \\
\hline & Tandem & 1 & $5 *$ & 3 & 14 & 8 & 38 & 2 & 8 & 6 & 26 & 2 & 8 & 22 & 16 \\
\hline \multirow[t]{2}{*}{ Dynamic balance } & Gait & 0 & 0 & 1 & 5 & 2 & 10 & 0 & 0 & 1 & 4 & 0 & 0 & 4 & 2 \\
\hline & Jumping & 4 & 19 & 0 & 0 & 1 & 5 & 2 & 8 & 2 & 9 & 1 & 4 & 10 & 7 \\
\hline Global motor & Hop-scotch & 8 & 38 & 9 & 43 & 13 & 62 & 11 & 44 & 6 & 26 & 6 & 25 & 53 & 39 \\
\hline coordination & Skipping rope & 15 & 71 & 14 & 67 & 18 & 86 & 20 & 80 & 18 & 78 & 22 & 92 & 107 & 79 \\
\hline \multirow[t]{2}{*}{ Perceptual-motor } & Key & 1 & 5 & 2 & 10 & 1 & 5 & 1 & 4 & 0 & 0 & 3 & 13 & 8 & 6 \\
\hline & Pyramid & 17 & 81 & 19 & 90 & 18 & 86 & 21 & 84 & 18 & 78 & 20 & 83 & 113 & 83 \\
\hline Fine motor & Buttoning & 4 & 19 & 2 & 10 & 1 & 5 & 0 & 0 & 0 & 0 & 1 & 4 & 8 & 6 \\
\hline coordination & Simple knot & 14 & 67 & 15 & 71 & 15 & 71 & 14 & 56 & 9 & 39 & 12 & 50 & 79 & 58 \\
\hline Total & & 69 & 15 & 74 & 16 & 88 & 19 & 86 & 19 & 71 & 15 & 76 & 16 & 464 & \\
\hline
\end{tabular}

$M$, morning period; I, intermediate period; $A$, afternoon period; * $p<0.05$. 
the morning (Figs 1 and 2). Failure to perf o rm the sharpened Romberg (Tandem) test was observed for 9 boys (34\%) of the study group versus 1 boy $(5 \%)$ of the control group $(p<0.05)$.

With respect to the monopodal stance test, failu re was observed for 16 boys (62\%) of the study group versus $5(24 \%)$ of the control group ( $p<$ 0.05).

\section{DISCUSSION}

No data are available in the literature showing that sleep disorders influence the neuromotor development of preschool children. This was the objective of the present study which added evidence to investigations that report a probably influence of sleep disturbances on the acquisition of motor skills ${ }^{14,16,17}$. In this respect, we observed that boys studying in the morning showed more frequent alterations in static balance compared to the control group. Sleep disorders are common in early childhood and tend to persist during preschool years. The persistence of early childhood sleep disorders in this age group might reflect ch ronic medical conditions as well as the presence of environmental, family and behavioral problems ${ }^{1-17,20-25}$. However, data regarding sleep problems in childhood and particularly in preschool children are scarce.

Sleep disorders can influence cognitive, emotional and motor development and can cause physiologycal alterations in the central nervous system $1,4-5,7-17,20-25$. Some studies have demonstrated that selective sleep deprivation can impair the acquisition of a motor activity, with stage 2 nonREM sleep probably being involved in the motor skill gain obtained during the period before a night's sleep compared to the control group deprived of stage 2 sleep after motor training. Other studies have suggested that the learning of motor skills depends on REM sleep and slow-wave sleep, a fact that seems to be associated with the complexity of the learned skills, which are related to variations in cortical plasticity ${ }^{14}$. Mnemonic processes during normal sleep are critically dependent on REM sleep integrity ${ }^{14}$. These findings are consistent with various animal-learning paradigms showing that, after learning, REM sleep deprivation impairs the acquisition and long-term retention of motor skills and tasks ${ }^{16}$.

The present study adds further evidence for the fact that sleep disorders, in addition to compro- mising cognitive processes, also impair some motor skills. In addition, our data add two other variables that were apparently important in the development of balance difficulties observed in the present children, since boys who studied in the morning performed worse than the control group. Besides some girls were also affected by the same variables, there is no obvious reason to explain why boys are more affected; however, in similar cultural contexts girls aged 4-5 to 17 years, in contrast to boys, predominantly develop skills such as static and dynamic balance, agility, manual skills and jumping with monopodal support ${ }^{26}$.

The observation of a larger number of altere $d$ tests for children studying in the morning suggests that factors such as sleep restriction are important in the development of these motor difficulties, considering that total nocturnal sleep time is longer in children attending school in the intermediate or afternoon period than in those attending in the morning ${ }^{4-6,8,11}$. As practical issue we should consider the above variables while performing neu rogical examination in children especially in the morning.

Based on evolutive neurological tests ${ }^{27}$ and psychomotor fundaments, we evaluated the childre $n$ according to the stage of motor development using toys as instruments, which are easily applicable and provide an interaction with the "playing" environment for the children.

The main weakness of our study is related to the diagnosis of sleep disorders based on the use of questionnaires. Although these instruments are adequate for population studies, their low sensitivity and specificity may probably have influenced the present results. Individual clinical and polysomnographic assessment would permit the formation of more homogenous groups (study and control), and the eventual detection of motor difficulties in many other tests used.

\section{REFERENCES}

1. Convertini G. Transtornos del sueno en ninos sanos. A rch Argent Pediatr 2003;101:99-105.

2. Kataria S, Swanson MS, Trevathan, GE. Persistence of sleep disturbance in preschool children. J Pediatr 1987;110:642-646.

3. Stores G. Practitioner review: assessment and treatment of sleep disorders in children and adolescents. J Child Psychol Psychiatry 1996; 37:907-925.

4. Carvalho LC, Prado LF, Silva L, et al. Cognitive disfunction in 225 children 7 to 10 years old with sleep disorders. Sleep 2002;25:316.

5. Carvalho LBC, Prado LBF, Silva L, et al. Cognitive dysfunction in children with sleep disorders. Arq Neuropsiquiatr 2004;62:212-216.

6. Silva TA, Carvalho LBC, Almeida MM, et al. Hábitos de sono em crianças brasileiras de 7 a 10 anos de idade. Hypnos 2003;3:96-97. 
7. Simonds JF, Parraga H. Prevalence of sleep disorders and sleep behaviours in children and adolescents. J Am Acad Child Psychiatry 1982;21:383-388.

8. Moran CA, Carvalho LC, Prado LBF, et al. Sleep disorders and starting time to school impair fine motor coordination in 5 years old children. Sleep 2004;27:A111-A112.

9. Stein MA, Mendelsohn J, Obermeyer WH, Amromin J, Benca R. Sleep and behavior problems in school-aged children. Pediatrics 2001;107:1-9.

10. Thunstron M. Severe sleep problems in infancy associated with subsequent development of attention-deficit/hyperactivity disorder at 5.5 years of age. Acta Paediatr 2002;91:584-592.

11. Carvalho LBC, Prado LBF, Silva L, et al. Cognitive dysfunction in children with sleep-disordered breathing. J Child Neurol 2004 (in print).

12. Brien ML, Holbrook CR, Mervis CB, et al. Sleep and neurobehavioral characteristics of 5-to-7-year-old children with parentally reported symptoms of attention-deficit/hyperactivity disorder. Pediatrics 2003;111:554-563.

13. Simonds JF, Parraga, H. Sleep behavior and disorders in children and adolescents evaluated at psychiatric clinics. Dev Behav Pediatrics 1984;5:6-10.

14. Walker PM, Brakefield T, Morgan A, Hobson JA, Stickgold Robert. Practice with sleep makes perfect: sleep-dependent motor skill learning. Neuron 2002;35:205-211.

15. Allen RP. Development of the human circadian cycle. In Loughlim GM, Carrol JL, Marcus CL (eds). Sleep and Breathing in children. New York: Marcel Dekker Inc, 2000:313-328.

16. Karni A, Tanne D, Rubenstein BS, Askenasy JJM, Sagi D. Dependence on REM sleep of overnight improvement of a perceptual skill. Science 1994;265:679-682.
17. Sher A, Ratson M. Motor development and sleep problems among 9month-olds. Percep Motor Skill 1998;87:1218.

18. B runi $\mathrm{O}$, Ottaviano $S$, Guidetti $V$, et al. The sleep disturbance scale for child ren(SDSC) construction and validation of an instrument to evaluate sleep disturbances in childhood and adolescence. J Sleep Res 1996;5:251-261.

19. Costallat DM. Psicomotricidade: a coordenação visomotora e dinâmica manual da criança infradotada - método de avaliação e exercitação gradual básica. Rio de Janeiro: Editora Globo, 1978:136-138.

20. Ali NJ, Pitson DJ, Stradling JR. Snoring, sleep disturbance, and behaviour in 4-5 year olds. Arch Dis Child 1993;68:360-366.

21. Estivill E. Childhood insomnia due to disorderly habits. Rev Neurol 2000;30:188-191.

22. Guilleminault C, Winkle R, Korobkin R, Simmons B. Children and nocturnal snoring: evaluation of the effects of sleep relatedrespiratory resistive load and daytime functioning. Eur J Pediatr 1982;139:165-171.

23. Prado LBF, Cardeal JO, Cardeal M, Prado GF. Ronco em crianças. Rev Neurociências 2002;10:17-23.

24. Salzarulo P, Faglioli I. Sleep for development or development for waking? Some speculations from a human perspective. Behav Brain Research 1995;69:23-27.

25. Tavares SMA. Distúrbios do sono. Pediatria Moderna 1992;28:329-332.

26. Pérez RLM, Sanz GJL. Competencia motriz y género entre los escolares espanoles. Rev Int Med Cienc Arct Fís Deporte 2003;10 (cdeporte.rediris. es/revista10/artcompetencia.html).

27. Lefevre AB. Exame neurológico evolutivo do pré-escolar normal. São Paulo: Editora Sarvier, 1972. 